\title{
Degradation of nitrocellulose-based paint by Desulfovibrio desulfuricans ATCC 13541
}



a Dipartimento di Scienze e Tecnologie Alimentari e Microbiologiche, Università degli Studi di Milano, Via Celoria 2, 20133 Milan, Italy.

b Dipartimento di Chimica, Materiali e Ingegneria Chimica 'Giulio Natta', Politecnico di Milano, Via Mancinelli 7, 20133 Milan, Italy.

c Departamento de Edafología y Química Agrícola, Universidad de Santiago de Compostela, 15782 Santiago de Compostela, Spain.

*Correspondence: Francesca Cappitelli, Phone: +39-0250319121. Fax: +39-0250319238. E-mail: francesca.cappitelli@unimi.it

\begin{abstract}
Nitrocellulose is one of the most commonly used compounds in ammunition and paint industries and its recalcitrance to degradation has a negative impact on human health and the environment. In this study the capability of Desulfovibrio desulfuricans ATCC 13541 to degrade nitrocellulose as binder in paint was assayed for the first time. Nitrocellulose-based paint degradation was followed by monitoring the variation in nitrate, nitrite and ammonium content in the culture medium using ultraviolet-visible spectroscopy. At the same time cell counts and ATP assay were performed to estimate bacterial density and activity in all samples. Infrared spectroscopy and colourimetric measurements of paint samples were performed to assess chemical and colour changes due to the microbial action. Microscope observations of nitrocellulose-based paint samples demonstrated the capability of the bacterium to adhere to the paint surface and change the paint adhesive characteristics. Finally, preliminary studies of nitrocellulose degradation pathway were conducted by assaying nitrate- and nitrite reductases activity in $D$. desulfuricans grown in presence or in absence of paint. We found that $D$. desulfuricans ATCC 13541 is able to transform nitrocellulose as paint binder and we hypothesised ammonification as degradation pathway. The results suggest that $D$. desulfuricans ATCC 13541 is a good candidate as a nitrocellulose-degrading bacterium.
\end{abstract}

Keywords: nitrocellulose; paint; microbial degradation; Desulfovibrio desulfuricans; sulphate-reducing bacteria 


\section{Introduction}

Nitrocellulose, one of the most important and oldest cellulose derivative, is principally used as binder in paint and a bulk ingredient in gunpowder formulations (Auer et al. 2005). In addition, many materials commonly used in daily life, such as printing inks, decorative films, and pharmaceuticals, contain nitrocellulose (El-Diwani et al. 2009; Souza et al. 2005). The explosive and toxic properties of nitrocellulose and its recalcitrance to degradation make the compound harmful for human health and the environment (ElDiwani et al. 2009; Freedman et al. 1996; Souza et al. 2005). In this respect, although nitrocellulose wastes from industries (e.g. ammunition material and paint industries) and household hazardous waste, which consists of waste from a number of household products, contain increasing nitrocellulose content, only limited research effort into nitrocellulose waste treatment have been reported (Auer et al. 2005; El-Diwani et al. 2009; Freedman et al. 2002; Petrova et al. 2002; Slack et al. 2005; Souza et al. 2005).

Currently, the disposal of nitrocellulose is carried out by different processes, including membrane separation processes to enhance recovery of the fines, detonation, incineration and controlled low temperature thermal denitration, but these treatments produce dangerous airborne particulates and pan residues containing toxic materials (Auer et al. 2005; Freedman et al. 2002). Biological methods are used in the decontamination of pollutants because biotransformation could produce environmentally safe products at potentially lower costs in comparison to physical and chemical treatment processes (El-Diwani et al. 2009; Freedman et al. 1996) and therefore could be promising for nitrocellulose degradation (Freedman et al. 1996). Microorganisms are able to degrade nitrocellulose by two pathways: i) cleavage of $\beta-1,4$-glucoside bonds that produces nitrooligosaccharides of various length, normally carried out by fungi (Auer et al. 2005; Freedman et al. 2002; Petrova et al. 2002; Tarasova et al. 2004), and ii) nitrocellulose denitration that reduces the degree of nitro substitution, generally performed by bacteria (El-Diwani et al. 2009; Petrova et al. 2010; Tarasova et al. 2004; Tarasova et al. 2005). Since nitrooligosaccharides have mutagenic properties (Petrova et al. 2002), the second pathway is preferred over the first for exploitation as a biodegradation pathway. It has been reported that nitrocellulose undergoes degradation by methanogenic or sulphate-reducing bacteria under anaerobic conditions (Freedman et al. 2002; Petrova et al. 2010; Tarasova et al. 2005). Sulphate-reducing bacteria of the genus Desulfovibrio were reported to decrease the amount of nitrocellulose powder in media containing this compound (Petrova et al. 2010; Tarasova et al. 2009). The study by Petrova et al. (2006) reported the presence of nitrate in the culture media containing nitrocellulose, due to the nitroesterase activity of $D$. desulfuricans 1388. The subsequent nitrate disappearance and ammonium appearance indicated the dissimilatory reduction of nitrate to ammonium (Bursakov et al. 1997; Petrova et al. 2006; Petrova et al. 2002; Tarasova et al. 2004), a process involving nitrate reduction to nitrite and the subsequent nitrite reduction to ammonium by nitrate- and nitrite reductases (Bursakov et al. 1997; Kraft et al. 2011; Moura et al. 2007). There are several sulphate-reducing bacteria able to reduce nitrate to nitrite (Marietou et al. 2009; Moura et al. 1997), but it appears that this is not a shared feature across the genus Desulfovibrio (Marietou et al. 2009; Tarasova et al. 2009). In contrast, the dissimilatory reduction of nitrite to ammonium seems to be widespread in Desulfovibrio, which can synthesise a very active, constitutive nitrite reductase (Marietou et al. 2009; Moura et al. 2007).

To date, studies on nitrocellulose biodegradation have been performed on nitrocellulose powder, with a percentage of nitro groups of being more than $12 \%$, the percentage generally used in the military sector (Auer et al. 2005; Freedman et al. 2002; Petrova et al. 2002; Tarasova et al. 2009; Tarasova et al. 2004). To the best of our knowledge there are no reported studies on the biodegradation of nitrocellulose as component of daily life materials, like nitrocellulose-based paints. The biodegradation of paints is also interesting because substances other than nitrocellulose are present that could interfere with the degradation process. Although the bulk of a paint is pigment and binder, which is the film-forming material in which the pigment particles are dispersed and forms the matrix that binds the pigments on the painted surface, other components like metals, solvent and additives, are present in paint formulations (Cappitelli et al. 2005). 
The main aim of this work was to study the capability of Desulfovibrio desulfuricans ATCC 13541 to attack nitrocellulose as binder in paint. Ultraviolet-visible and infrared spectroscopy, microscope observations and reflectance colour techniques were used to correlate nitrocellulose degradation to specific chemical changes in the composition of the paint material. In addition, a preliminary study on the nitrocellulose degradation pathway in Desulfovibrio desulfuricans ATCC 13541 was conducted.

\section{Material and methods}

Nitrocellulose-based paint and paint sample preparation

The $20^{\text {th }}$ century paint binders are generally made of synthetic and semi-synthetic polymers including nitrocellulose (Buzzini and Massonnet 2004; Govaert and Bernard 2004; Zieba-Palus 2005). The red spray paint by Motip-Dupli ${ }^{\circledR}$ Autocolor (colour 5-0200) was selected in this study since most of red spray paints are composed of alkyd-nitrocellulose-based binders, including those produced by Motip ${ }^{\circledR}$ (Govaert and Bernard 2004; Segalini et al. 2000). Autocolor paint samples were prepared spraying the paint on plain glass slides (Prestige, $7.6 \times 2.6 \mathrm{~cm}$ ). The can was firstly shaken for 3 min per manufacturer's instruction and then the paint sprayed by a moving rate of about $20 \mathrm{~cm} / \mathrm{s}$, maintaining nozzle at a distance of $30 \mathrm{~cm}$ above the glass slide and the manual pressure on spray valve fixed to allow a uniform spread (Segalini et al. 2000). The amount of paint sprayed was $5.15 \pm 0.93 \mathrm{mg}$ with a paint layer thickness $<50 \mu \mathrm{m}$. The painted slides were dried for four months prior to their use in degradation experiments. For each experiment a constant ratio of $4.55 \mathrm{~mm}^{2}$ of Autocolor paint per $1 \mathrm{ml}$ of cultural medium was used.

\section{Degradation experiment}

The sulphate-reducing bacterium Desulfovibrio desulfuricans ATCC 13541 was selected for all the degradation experiments. D. desulfuricans was maintained anaerobically in DSMZ 63 medium (Cappitelli et al. 2006), while experiments were performed in modified medium containing half the standard sulphate content. Sulphates were not completely omitted as they may help nitrocellulose degradation (Marietou et al. 2009; Tarasova et al. 2009). Degradation experiments were performed in triplicate with the three following samples: D. desulfuricans cells in the culture medium and an Autocolor painted slide (sample A); the culture medium without microorganisms and an Autocolor painted slide (sample B), analysed to detect any contamination occurrence, and D. desulfuricans cells in the culture medium (sample C). The initial cell concentration was $10^{7}$ cells $/ \mathrm{ml}$ and the Autocolor painted slide was held static at $90^{\circ}$.

All samples were incubated for 49 days at room temperature under anaerobic conditions with a normal daily light-dark cycles and analysed at the beginning and at the end of the incubation period. To monitor bacterial density and activity in all samples, a cell count using the Thoma counting chamber and an ATP assay, performed according to Ranalli et al. $(2003$; 1998), except for the Tris- $\mathrm{HCl}$ buffer solution $(10 \mathrm{mM}, \mathrm{pH} 7.75)$, were achieved.

\section{Nitrate, nitrite and ammonia concentration tests and $\mathrm{pH}$ measurements}

Nitrate, nitrite and ammonia contents in the culture medium were evaluated by ultraviolet-visible spectroscopy using a UV/Vis 6705 Spectrophotometer (Jenway, UK). Samples were firstly filtered using a $0.22 \mu \mathrm{m}$ membrane (Millipore, Italy) to eliminate bacterial cells and precipitated FeS particles produced by them that could interfere with the readings. Nitrate and nitrite content was assayed according to APHA et al. (1998) except for nitrite assay, where the sample volume used has been $1 \mathrm{ml}$. Ammonia concentration was determined using the Nessler reagent (Merck, Germany). The colourimetric reaction was performed by adding $2 \mu \mathrm{l}$ sodium-potassium tartrate and $20 \mu \mathrm{l}$ Nessler reagent to $1 \mathrm{ml}$ of sample. After $15 \mathrm{~min}$, absorbance 
was evaluated at $420 \mathrm{~nm}$. The nitrate, nitrite and ammonia nitrogen $\left(\mathrm{NO}_{3}{ }^{-}-\mathrm{N}, \mathrm{NO}_{2}{ }^{-}-\mathrm{N}\right.$ and $\mathrm{NH}_{3}-\mathrm{N}$, respectively) concentrations were calculated using calibration curves previously obtained.

$\mathrm{pH}$ measurement was performed using a $\mathrm{pH}$ indicator strip (Merck, Germany) at $25^{\circ} \mathrm{C}$, in order to confirm the variation of the nitrogen forms in the culture medium of all samples.

Analysis of variance (ANOVA) via MATLAB software (Version 7.0, The MathWorks Inc, Natick, USA) was applied to evaluate statistically significant differences among samples $\mathrm{A}, \mathrm{B}$ and $\mathrm{C}$ at the beginning $(0$ day) and at the end (49 days) of the experiment. Tukey honestly significant different test (HSD) was used for pairwise comparison to determine the significance of the data. Statistically significant results were depicted by $\mathrm{p}-$ values $<0.05$.

\section{FT-IR spectroscopy}

To detect nitrocellulose presence, Autocolor painted slides not subjected to any treatment (sample D) were analysed. Autocolor painted slides, held in the medium with and without cells (sample A and B, respectively), were analysed using a Nicolet 6,700 spectrophotometer equipped with a DTGS detector or coupled with a Nicolet Continuum FTIR microscope equipped with an $\mathrm{HgCdTe}$ detector cooled with liquid nitrogen. Samples were analysed in attenuated total reflectance (ATR) and as $\mathrm{KBr}$ pellets to verify the presence of organic compounds related to bacterial metabolism and changes in the paint chemical formulation.

FTIR analyses were recorded between 4,000 and $700 \mathrm{~cm}^{-1}$ (HgCdTe detector) or 4,000 and $400 \mathrm{~cm}^{-1}$ (DTGS detector) with 128 acquisitions and $4 \mathrm{~cm}^{-1}$ resolution. The spectra were baseline corrected using the Omnic software, and normalised, when necessary, by setting the absorbance of a specific peak to a desired value.

Prior to the analysis, Autocolor painted slides were washed three times with phosphate buffer, to remove any traces of culture medium and then dried for one month at room temperature, to further remove any surfacebound water molecules that could interfere with the spectroscopic measurements.

\section{Determination of colour variations}

Reflectance colour measurements of Autocolor painted slides from sample A were performed to assess the capability of $D$. desulfuricans to modify the colour of the spray paint. Autocolor painted slides not subjected to any treatment (sample D) were considered in this experiment. This sample, prepared in triplicate as described in "Nitrocellulose-based paint and paint sample preparation" subsection, was considered as the colour reference. Colour measurements were performed according to Sanmartin et al. (2011), carrying out five measurements at random positions on an area of approximately $9.88 \mathrm{~cm}^{2}(3.8 \times 2.6 \mathrm{~cm})$ of samples A and D, by use of a Konica Minolta colourimeter with a CR-300 measuring head (8-mm-diameter viewing area). The colour measurements were analysed by considering the CIELAB colour system (CIE 1986), which represents each colour by means of three scalar parameters or Cartesian coordinates: L*, lightness or luminosity of colour, which varies from 0 (absolute black) to 100 (absolute white); a*, associated with changes in redness-greenness (positive $a^{*}$ is red and negative $a^{*}$ is green); and $b^{*}$, associated with changes in yellowness-blueness (positive $b^{*}$ is yellow and negative $b^{*}$ is blue). Alternatively, each colour is represented by means of three angular parameters or cylindrical coordinates, most closely related to the psychophysical perception of the colour: $\mathrm{L}^{*}$, lightness or luminosity of colour, also defined in both scalar and angular colour sets; chroma $C^{*}{ }_{a b}=\sqrt{a^{* 2}+b^{* 2}}$ related to the intensity of colour or saturation and hue angle $h_{a b}=\arctan (b * / a *)$ or tone of colour which refers to the dominant wavelength and indicates redness, yellowness, greenness, or blueness on a circular scale, starting at $0^{\circ}$ and increasing counter clockwise (Wyszecki and Stiles 1982). Furthermore, the partial ( $\Delta \mathrm{L}^{*}, \Delta \mathrm{a}^{*}, \Delta \mathrm{b}^{*}, \Delta \mathrm{C}^{*}{ }_{\mathrm{ab}}$ and $\left.\Delta \mathrm{H}^{*}{ }_{\mathrm{ab}}\right)$ and the total $\left(\Delta \mathrm{E}^{*}{ }_{\mathrm{ab}}\right)$ colour differences between samples A and D of the Autocolor painted slides were calculated. The total colour difference was expressed as $\Delta E^{*}{ }_{a b}=\sqrt{\left(\Delta L^{*}\right)^{2}+\left(\Delta a^{*}\right)^{2}+\left(\Delta b^{*}\right)^{2}}$ or $\Delta E_{a b}^{*}=\sqrt{\left(\Delta L^{*}\right)^{2}+\left(\Delta C^{*}{ }_{a b}\right)^{2}+\left(\Delta H^{*}{ }_{a b}\right)^{2}}$, where $\Delta \mathrm{L}^{*}, \Delta \mathrm{a}^{*}, \Delta \mathrm{b}^{*}$ and $\Delta \mathrm{C}^{*}{ }_{\mathrm{ab}}$ represent respectively the 
differences between the values of $\mathrm{L}^{*}, \mathrm{a}^{*}, \mathrm{~b}^{*}$ and $\mathrm{C}^{*}{ }_{\mathrm{ab}}$ belonging to samples $\mathrm{A}$ and $\mathrm{D}$, and $\Delta \mathrm{H}^{*}{ }_{\mathrm{ab}}$ is given by $\Delta H{ }_{a b}=2 \cdot \sqrt{C *_{1} \cdot C{ }_{2}} \cdot \sin \left(\Delta h_{a b} / 2\right)$, where $\Delta \mathrm{h}_{\mathrm{ab}}$ is the difference in hue angle $\Delta h_{a b}=\tan ^{-1}\left(b *_{2} / a *_{2}\right)-\tan ^{-1}\left(b *_{1} / a *_{1}\right)$ and the subscripts 1 and 2 represent samples D and A respectively.

Multivariate analysis of variance (MANOVA) and the Tukey-B multiple comparison test, via SPSS software (version 15.0) were applied to compare separately each CIELAB colour coordinates $\left(L^{*}, a^{*}, b^{*}, C^{*}{ }_{a b}\right.$ and $\mathrm{h}_{\mathrm{ab}}$ ) among Autocolor painted slides of samples A and D. Statistically significant results were depicted by $\mathrm{p}-$ values $<0.05$.

\section{Stereomicroscope and epifluorescence microscope observations}

Stereomicroscope observations of the Autocolor painted slides (samples A and B) were performed using a Leica M205C stereomicroscope equipped with a Leica DFC 290 video camera, to visualise macroscopic changes in the paint film and its adhesion on the surface of the glass slide. Morphological studies of the film were carried out at different magnifications.

To evaluate the $D$. desulfuricans capability to attach onto the paint surface, a DAPI staining of samples A and B was performed according to Giacomucci et al. (2011). Epifluorescence observations were carried out with a Leica DM4000B digital epifluorescence microscope equipped with Cool-Snap CF camera (Photometrics, Roper Scientific) and pictures were acquired using RS Image ver. 1.7.3 software (Roper Scientific).

Nitrate- and nitrite reductase activity evaluation

To evaluate nitrate- and nitrite reductase activity in $D$. desulfuricans incubated in the presence of nitrocellulose as binder of Autocolor paint, the bacterium grew for 49 days at $25^{\circ} \mathrm{C}$ in DSMZ 63 medium modified as previously described in "Degradation experiment" subsection with or without Autocolor painted slides.

\section{Total protein extraction and enzyme assay}

D. desulfuricans cells were harvested by centrifugation at 7,000 rpm for $15 \mathrm{~min}$ at $4{ }^{\circ} \mathrm{C}$ washed two times in phosphate buffer and suspended in $0.1 \mathrm{M}$ phosphate buffer, $\mathrm{pH} 7.6$, in a ratio $1 / 8$ (weight/volume). Total proteins were extracted by sonication performed in 5 cycles of $30 \mathrm{~s}$ at $55 \%$ power and after 1 min of stop. The extract was centrifuged at $11,000 \mathrm{rpm}$ for $30 \mathrm{~min}$ at $4^{\circ} \mathrm{C}$ to eliminate cellular debris. Protein concentration in the crude extract was determined using the Bradford method (Bradford 1976).

The nitrate reductase activity was assayed at $37^{\circ} \mathrm{C}$ in $0.5 \mathrm{M}$ phosphate buffer at $\mathrm{pH}$ 7.6. The reaction mixture and the protocol were conducted as reported by Bursakov et al. (1997), except for the use of $15 \mathrm{mM} \mathrm{KCN}$. The nitrate concentration was then measured as described in "Nitrate, nitrite and ammonia concentration tests and pH measurements" subsection. The nitrite reductase activity was assayed as by Liu et al. (1994), except for the termination of the reaction that was achieved by vigorously shaking of the reaction tube. The nitrite concentration was then measured as described in "Nitrate, nitrite and ammonia concentration tests and pH measurements" subsection. The enzymatic unit is defined by $\mu$ mol of substrate reduced per minute. To evaluate statistically significant differences among enzymatic activities the t-test, via Microsoft Excel tool for Windows, was applied. Statistically significant results were depicted by $\mathrm{p}-\mathrm{values}<0.05$. 


\section{Results}

Characterisation of Autocolor® paint

Autocolor film (Sample D) was analysed by FTIR spectroscopy for the identification of the main component of the polymeric blend. The main component of the resin is nitrocellulose and an alkyd fraction (a modified polyester resin) was also present. The characteristic and diagnostic FTIR peaks of nitrocellulose are related to the $\mathrm{N}-\mathrm{O}$ vibration at $1,655 \mathrm{~cm}^{-1}$ and $1,280 \mathrm{~cm}^{-1}$, while the polyester resin has the characteristic vibration peaks at $1,735 \mathrm{~cm}^{-1}(\vee \mathrm{C}=\mathrm{O})$ and $1,073 \mathrm{~cm}^{-1}(\vee \mathrm{C}-\mathrm{O})$, both related to the ester group of the polymer.

The complete characterisation of other components, like pigment, stabiliser or other additives, was beyond the aim of this work.

Degradation experiment

Cell counts and ATP content of samples A and C carried out at both the beginning and at the end of the experiments were not significantly different (Figure 1a and 1b). Investigations performed on sample B showed that there was no occurrence of contamination during the incubation period (Figure 1b). UV-Vis spectrophotometric measurements performed in the culture medium showed a decrease in nitrate (Figure 1c) and nitrite (Figure 1d) concentration in samples $\mathrm{A}$ and $\mathrm{C}$ in comparison to sample $\mathrm{B}$, where they were significantly higher and an increase in ammonia concentration in all three samples (Figure 1e). The final ammonia concentration was not significantly different across all 3 samples (Figure 1e). These results were in agreement with a $\mathrm{pH}$ increment in the same sample (data not shown).
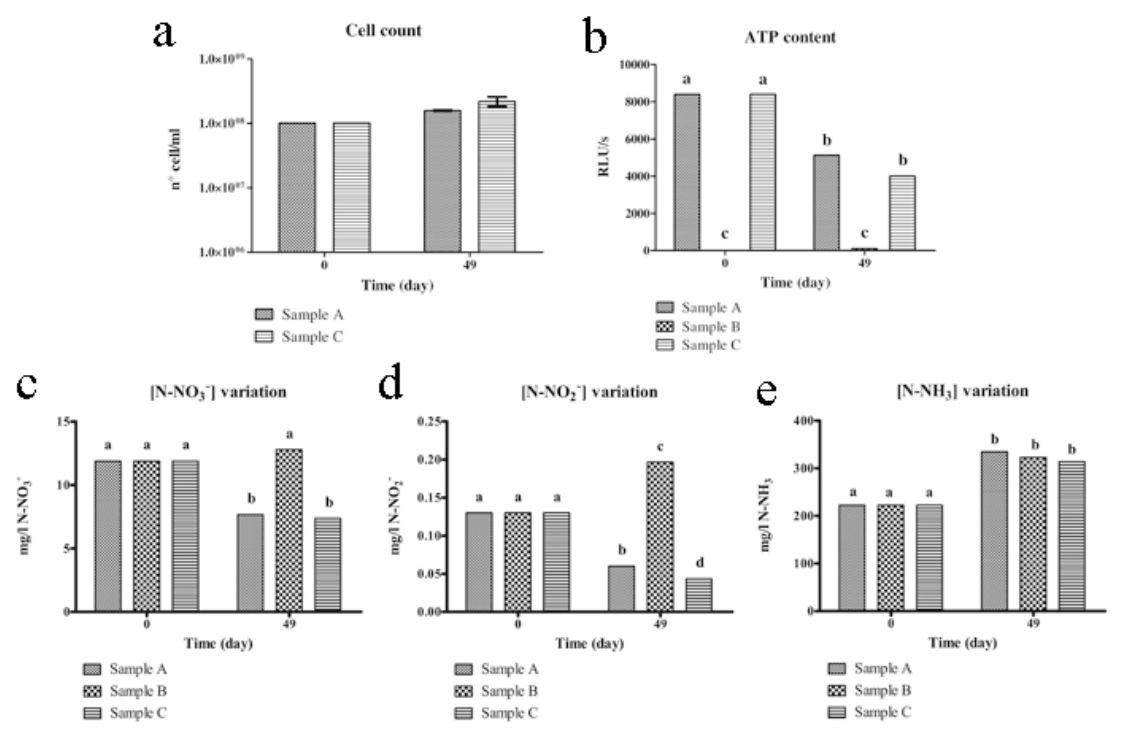

Fig. 1 Variation of cell concentration of samples A and C, ATP content and nitrogen forms concentration in the culture medium of samples $A, B$ and $C$ at the beginning ( 0 day) and at the end (49 days) of the experiments. (a) Cell count (error bars represent standard deviation), (b) ATP content (p-value $=5.55 \times 10-16$ ), (c) nitrate nitrogen $(p-$ value $=1.30 \times 10-13),(d)$ nitrite nitrogen $(p-v a l u e=0)$, and $(e)$ ammonia nitrogen $(p-v a l u e=$ $2.45 \times 10-11)$ concentrations. The histograms represent average values from three independent replicates. According to post-hoc analysis, means sharing the same letter are not significantly different from each other

\section{FTIR and FTIR-ATR spectroscopy}

Bacterial growth and the degradation phenomenon were analysed by FTIR spectroscopy in KBr transmission and ATR. Since transmittance FTIR on KBr pellets shows the absorbance of the bulk material, this was the most adequate technique to investigate the bacterial degradation of the Autocolor paint. As FTIR-ATR 
analyses give information about surface phenomena they showed that bacteria have colonised the polymeric surface.

Acquired spectra were baseline corrected and normalised on the $\mathrm{C}-\mathrm{H}$ stretching area using the $2,960 \mathrm{~cm}^{-1}$ peak, related the $\mathrm{CH}_{3}$ asymmetric stretching vibration of the polyester component, which is expected to be the more stable component.

The paint was partially affected by the prolonged immersion in the aqueous culture medium, visible by the slow reduction in the intensity of signal related to the nitric substituent (peaks at $1,655 \mathrm{~cm}^{-1}$ and $1,280 \mathrm{~cm}^{-1}$ ), suggesting a partial abiotic denitrification process. Furthermore, the polyester component was also slightly affected by the prolonged contact with the buffer as was evident by the reduced intensity of the $\mathrm{C}=\mathrm{O}$ stretching peak at $1,735 \mathrm{~cm}^{-1}$ and the $\mathrm{C}-\mathrm{O}$ stretching vibration at $1,073 \mathrm{~cm}^{-1}$, both related to the ester group of the main chain.

The comparison between sample D and sample A FTIR-ATR spectra showed an increase in signal related to amide groups at $1,540 \mathrm{~cm}^{-1}$ (see black arrow in Figure 2a). The presence of proteinaceous material was also confirmed by the increase of signal in the area between 900 and $1,100 \mathrm{~cm}^{-1}$, related to $\mathrm{C}-\mathrm{N}$ and $\mathrm{N}-\mathrm{N}$ stretching vibrations in nitrogen compounds. Furthermore, the relative intensity of the peak at $1,280 \mathrm{~cm}^{-1}$ (amide I signal) decreased due to degradation of the $\mathrm{N}-\mathrm{O}$ substituent. This decrease was not observed for the peak at $1,655 \mathrm{~cm}^{-1}$ (amide II signal) for the concurrent increase of the amine products which signal falls in the same range (see green arrows in Figure 2a). A noticeable increase in signal in the area from 3,000 to $3,700 \mathrm{~cm}^{-1}$ must be related to $\mathrm{NH}$ and $\mathrm{OH}$ stretching vibrations due to organic material.

The slight abiotic degradation recorded in the FTIR analysis of the KBr pellets was enhanced by the presence of bacteria which decreased the rate of nitrification of the cellulose-based paint leading to a considerable decrease of the signals at $1,655 \mathrm{~cm}^{-1}$ and $1,280 \mathrm{~cm}^{-1}$ (see black arrow in Figure $2 \mathrm{~b}$ ). The high specificity of the bacterial activity was also confirmed by the invariance of the $\mathrm{C}-\mathrm{N}$ stretching peak visible at $840 \mathrm{~cm}^{-1}$ which remained stable during all degradation experiments. The degradation of the modified polyester component (alkyd resin) was slightly enhanced suggesting a partial bacterial degradation which was evident by the depletion of the signals related to the ester group ( $\vee \mathrm{C}=\mathrm{O}$ at $1,735 \mathrm{~cm}^{-1}$ and $\vee \mathrm{C}-\mathrm{O}$ at $1,073 \mathrm{~cm}^{-1}$ ).
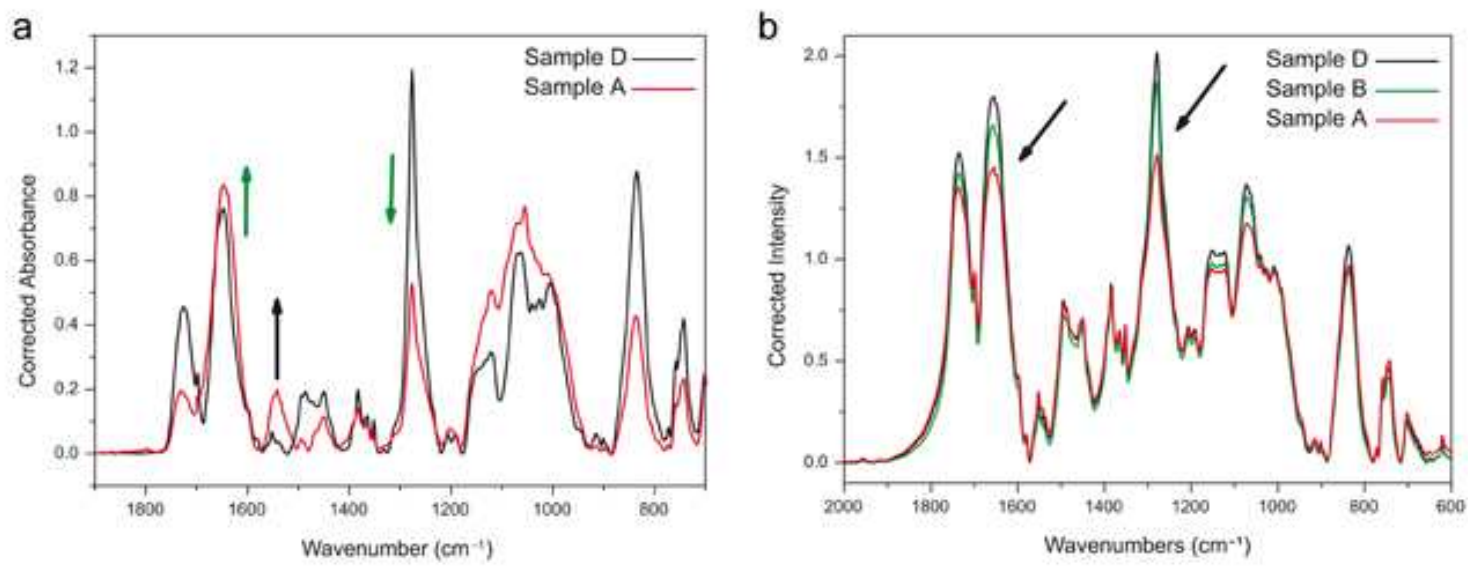

Fig. 2 (a) FTIR ATR spectra of the Autocolor film (sample D) and the degraded sample A in the range 1,900-700 $\mathrm{cm}^{-1}$. The arrows indicate the variation in intensity related to bacterial compounds on the film surface. (b) FTIR spectra of the Autocolor film (sample D), of the paint incubated with the culture medium (sample B) and incubated in the presence of bacteria (sample A). The arrows indicate the diagnostic peak for the degradation of the nitro-substituent in the nitrocellulose molecules

\section{Reflectance colour measurements}

Reflectance colour measurements of Autocolor painted slides (samples A and D) were performed in order to study $D$. desulfuricans ATCC 13541 capacity to change the spray paint colour. The mean values of the CIELAB colour coordinates, using the Cartesian $\left(\mathrm{L}^{*} \mathrm{a} * \mathrm{~b}^{*}\right)$ and cylindrical $\left(\mathrm{L}^{*} \mathrm{C}^{*}{ }_{\mathrm{ab}} \mathrm{h}_{\mathrm{ab}}\right)$ coordinates, in 
samples $A$ and D are shown in Figure 3a. Bacterial treatment led to a significant increase in lightness ( $\mathrm{L}^{*}$, from $41.6 \pm 0.6$ to $44.6 \pm 0.7$ ), a significant decrease in yellowness with a concomitant increase in blueness $\left(b^{*}\right.$, from $35.8 \pm 0.6$ to $29.8 \pm 1.0$ ) and a significant decrease in the tone of colour $\left(\mathrm{h}_{\mathrm{ab}}\right.$, from $34.0 \pm 0.3$ to $29.4 \pm 0.4$ ), which confirmed that $D$. desulfuricans ATCC 13541 caused Autocolor spray fading. To evaluate if these changes in colour were visible to the naked eye, the partial colour differences $\left(\Delta \mathrm{L}^{*}, \Delta \mathrm{a}^{*}, \Delta \mathrm{b}^{*}, \Delta \mathrm{C}^{*}{ }_{\mathrm{ab}}\right.$ and $\left.\Delta \mathrm{H}^{*}{ }_{\mathrm{ab}}\right)$ and total colour difference $\left(\Delta \mathrm{E}^{*}{ }_{\mathrm{ab}}\right)$ in presence of $D$. desulfuricans cells were calculated (Figure $3 b)$. The visual colour difference threshold or just noticeable difference (JND), which constitutes the lower limit of perception in an individual with normal colour vision (Brown 1957; Macadam 1942) established as 1 CIELAB unit (Wyszecki and Stiles 1982), was not overcome by the partial difference of the rednessgreenness parameter $\left(\Delta \mathrm{a}^{*}: 0.3\right.$ CIELAB units). The remaining colour differences exceeded this limit and also the value considered the general limit of perceptibility: 3 CIELAB units (Berns 2000; Prieto et al. 2010; Völz 2001), which is the upper limit of rigorous colour tolerance (Figure 3b). Even taking into account a higher threshold of perception of 6 CIELAB units, considered an evident colour change (Hardeberg 1999), the overall change in colour or total colour difference ( $\Delta \mathrm{E}^{*}{ }_{\mathrm{ab}}$ : $6.7 \mathrm{CIELAB}$ units) overcame also this value, and therefore the colour change as a result of $D$. desulfuricans ATCC 13541 can be considered noticeable at first glance.
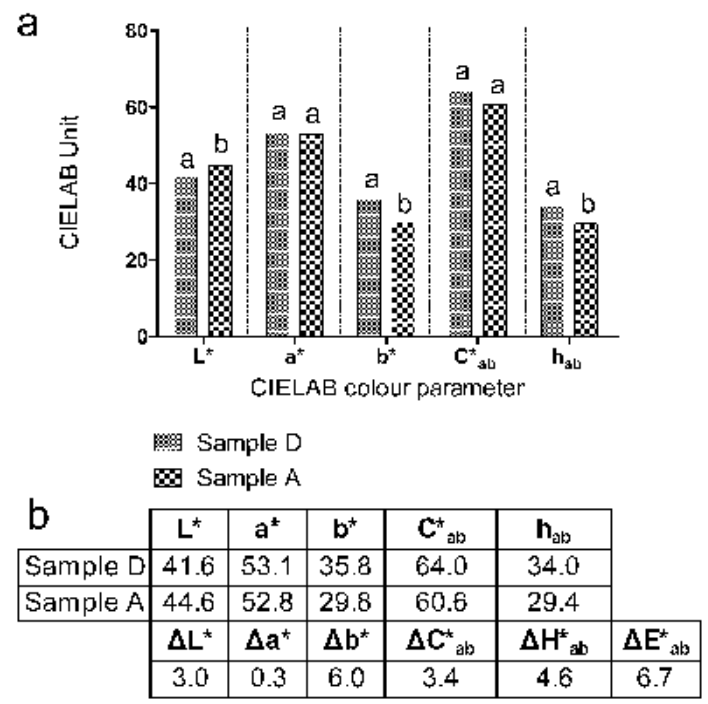

Fig. 3 (a) Mean CIELAB colour coordinates (CIELAB units). The histograms represent average values from 5 measurements from 3 independent Autocolor painted slides. Different letters showed on the top of the histograms indicate statistically significant differences ( $p-$ value < 0.05). (b) Mean CIELAB colour coordinates (CIELAB units) and partial and total colour differences between samples $D$ and $A$

\section{Stereomicroscope and epifluorescence microscope observations}

Pictures of Autocolor painted slides (samples A and B) at the end of the degradation experiment are shown in Figure 4. After bacterial treatment modifications on the surface of painted slides were visible (Figure 4a and $4 \mathrm{~d}$ ), and further investigated by microscope observations (Figure $4 \mathrm{~b}$ and $4 \mathrm{e}$ ). In particular, Autocolor painted slides treated with $D$. desulfuricans (sample A) showed paint detachment (Figure 4b) while biologically-untreated Autocolor painted slides (sample B) showed no alteration in the adhesive characteristic of the paint (Figure 4e). Moreover, epifluorescence microscopy observations of Autocolor painted slides after DAPI staining showed that $D$. desulfuricans was able to adhere to the surface of the paint layer of sample A (Figure 4c) while in sample B (Figure 4f) there was no fluorescence signal, confirming the absence of a microbial contamination. 


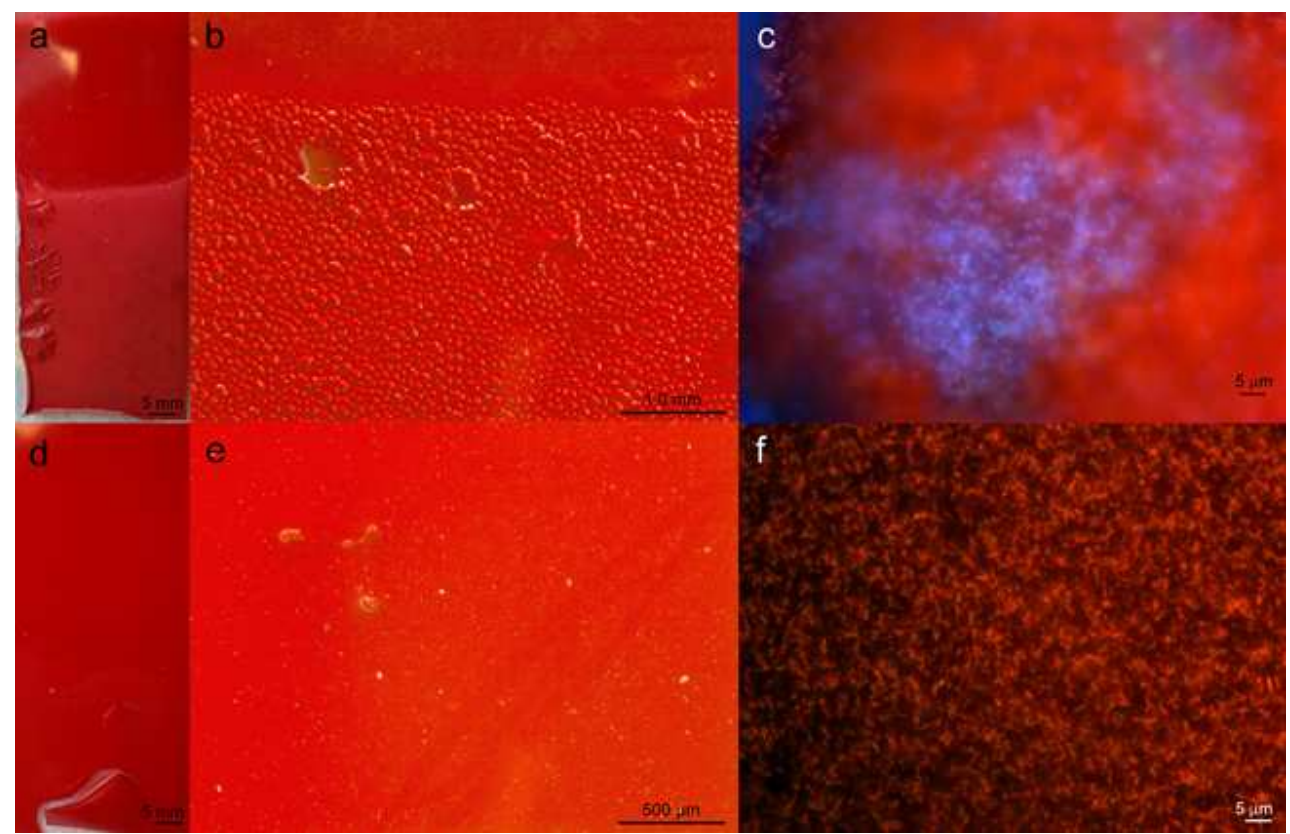

Fig. 4 Autocolor painted slides after 49 days of incubation with (a-c) or without (d-f) D. desulfuricans ATCC 13541 (samples A and B, respectively). (a, d) Pictures of Autocolor painted slides, the bottom half of the slide corresponds to the immersed part, $(b, e)$ stereomicroscope observations and $(c, f)$ epifluorescence observations after DAPI staining

Nitrate- and nitrite reductase activity

The nitrate reductase activity was similar for $D$. desulfuricans incubated with or without Autocolor painted slides, while nitrite reductase activity was significantly higher (p-value $<0.05$ ) when $D$. desulfuricans was incubated with Autocolor painted slides (Table 1).

\begin{tabular}{|l|c|l|}
\hline & $\begin{array}{c}\text { Autocolor } \\
+\end{array}$ & D. desulfuricans \\
\hline $\begin{array}{l}\text { Nitrate reductase } \\
\text { activity }\end{array}$ & $1089.91 \pm 29.10$ & $1059.33 \pm 34.13$ \\
\hline $\begin{array}{l}\text { Nitrite reductase } \\
\text { activity }\end{array}$ & $87.09 \pm 23.88 *$ & $35.18 \pm 17.92$ \\
\hline
\end{tabular}

Table 1 Enzyme activity values expressed in $\mu \mathrm{mol}$ of substrate reduced per minute. Asterisk indicates the result of t-test (p-value $<0.05$ ), which was performed separately for nitrate- and nitrite reductases activities

\section{Discussion}

Nitrocellulose wastes are recalcitrant to degradation and have a negative impact on human health and the environment (El-Diwani et al. 2009; Freedman et al. 1996; Souza et al. 2005) but there are bacteria that are able to remove the nitro groups from nitrocellulose, which renders the polymer residuals safer (El-Diwani et al. 2009; Petrova et al. 2010; Tarasova et al. 2004). To date, few studies have been conducted on nitrocellulose biodegradation and furthermore all those performed with bacteria have been conducted using nitrocellulose powder. In this study the capability of Desulfovibrio desulfuricans ATCC 13541 to degrade nitrocellulose as binder in paint was assayed for the first time. We selected D. desulfuricans ATCC 13541 principally because Desulfovibrio has been reported to be active against nitrocellulose (Petrova et al. 2002; 
Tarasova et al. 2004) and has been used in metal biosorption (Chen et al. 2000), and therefore the strain is resistant to the high concentrations of metals that can be encountered in paints. Long incubation times were used because Tarasova et al. (2005) observed a large decrease in nitro group content in nitrocellulose after 30 to 60 days of incubation.

In our studies, paint degradation was initially followed by evaluating changes in nitrate, nitrite and ammonium concentrations as previous studies of nitrocellulose degradation by Desulfovibrio spp., correlated these variations in nitrate and ammonium content to a nitroesterase activity (Petrova et al. 2006; Petrova et al. 2002; Tarasova et al. 2009; Tarasova et al. 2004).

Infrared spectroscopy is a very good technique for paint analysis (Buzzini and Massonnet 2004; Cappitelli et al. 2005) and was previously used to investigate paint components and also nitrocellulose changes during degradation by Desulfovibrio spp. (Govaert and Bernard 2004; Segalini et al. 2000; Tarasova et al. 2005; Zieba-Palus 2005). The paint used was firstly selected as putative nitrocellulose-based paint and then confirmed as a nitrocellulose- and alkyd-based paint. The capability of $D$. desulfuricans ATCC 13541 to adhere onto the surface of the paint, assessed by epifluorescence microscopy observations was further confirmed by FTIR-ATR spectroscopy that showed the presence of proteinaceous material on the painted surface. $D$. desulfuricans degradation activity against Autocolor paint was assessed even if slight abiotic degradation of the paint, as a consequence of the long immersion time in the culture medium, was recognisable. The presence of bacteria acted with high specificity on the $\mathrm{N}-\mathrm{O}$ bond of the nitro-substituted cellulose and implied a pronounced depletion of the related signal, suggesting that bacterial degradation favoured this chemical group compared to others.

After incubation with $D$. desulfuricans, we observed paint detachment and fading of Autocolor paint slides, both noticeable at first glance. Bacteria on painted surfaces can lead to paint detachment and discolouration (Cappitelli et al. 2009; Pepe et al. 2010). Although reflectance colour measurements were used to characterise paint colour objectively (Prieto et al. 2011), to date, no study concerning the colour change during paint biodegradation is available in the literature. In our case, although lightness increased significantly, greater changes occurred in other colour coordinates. The slightly increase in colour lightness can be explained by the ability of the metabolism of $D$. desulfuricans to convert sulphate to sulphides which, in the presence of iron (II) as a component of modified DSMZ 63 medium, form a black colour precipitate (Cappitelli et al. 2006). The colour fading of Autocolor paint, proved by changes in CIELAB colour parameters, could have been caused by the degradation of the paint binder, the removal of nitro groups from the nitrocellulose molecule and the degradation of other ingredients of the paint formulation.

According to Petrova et al. (2006; 2002) and Tarasova et al. (2004) nitrocellulose degradation by Desulfovibrio spp. occurs via dissimilatory nitrate reduction to ammonia. In this study, we found that the activity of nitrate reductase was equivalent in $D$. desulfuricans grown in the presence or in the absence of Autocolor paint. In the literature, there is little agreement concerning how nitrate reduction is regulated in sulphate-reducing bacteria, even in the well-studied Desulfovibrio genus (Marietou et al. 2009; Tarasova et al. 2009). Nitrate reductase genes are found only in some sulphate-reducing bacteria and various pathways of nitrate reduction regulation have been described (Marietou et al. 2009; Tarasova et al. 2009). In our experiments, we use a modified DSMZ 63 medium containing only half the normal concentration of sulphate, because four Desulfovibrio strains were reported to have constitutive nitrate reductase activity in media containing low concentrations of sulphate (Marietou et al. 2009; Tarasova et al. 2009). Other researchers (Keith and Herbert 1983; Seitz and Cypionka 1986) reported that for D. desulfuricans Essex strain the presence of sulphate is essential for nitrate reduction to occur. In contrast, the study on $D$. desulfuricans FBA 20 by Mitchell et al. (1986) reported that nitrate reduction occurs only in the absence of sulphate. This diversity within one genus probably results from differences in the structure of nitrate reductases or from subunit combinations in different bacteria (Tarasova et al. 2009); moreover, growth conditions may affect the activity of this enzyme (Marietou et al. 2009). Our experiments showed higher activity of nitrite reductase in $D$. desulfuricans grown in the presence of Autocolor paints rather than in $D$. desulfuricans grown without paint. Nitrite reductase has been reported to be expressed constitutively and 
involved in respiratory nitrate ammonification in Desulfovibrio spp. that are able to grow using nitrate as terminal electron acceptor, e.g. Desulfovibrio desulfuricans (Simon 2002), and in detoxifying reactions in those species incapable of using nitrite as a terminal electron acceptor, e.g. Desulfovibrio vulgaris Hildenborough (Haveman et al. 2004; Pereira et al. 2000). More recently nitrite reductase was considered responsible for metal reductase activity (Barton et al. 2007), and this is an important feature for paint degradation as paint formulations include components such as pigments, additives and impurities, which may contain metals (Stoye and Freitag 1998).

In conclusion our findings proved that $D$. desulfuricans ATCC 13541 is able to degrade nitrocellulose as binder in paint and likely performs this degradation by the ammonification pathway.

\section{Acknowledgements}

We thank Dr. Kevin J. Purdy, University of Warwick, for his helpful suggestions made in the course of this research. We also thank Edoardo Accattino for his technical assistance in protein extraction. This study has been partially financed by the Xunta de Galicia (09TMT014203PR) and Ministry of Science and Innovation (BES-2007-16996).

The authors want to thank Springer publishing for publishing the last version of this article. http://www.springerlink.com/openurl.asp?genre=article\&id=doi:10.1007/s10532-012-9546-9. The final publication is available at www.springerlink.com.

\section{References}

APHA, AWWA, WEF (eds) (1998) Standard methods for the examination of water and wastewater, vol 4-113/4-114. XX edn. APHA, Washinghton

Auer N, Hedger JN, Evans CS (2005) Degradation of nitrocellulose by fungi. Biodegradation 16 (3):229-236. doi:10.1007/s10532-004-0896-9

Barton LL, Goulhen F, Bruschi M, Woodards NA, Plunkett RM, Rietmeijer FJM (2007) The bacterial metallome: composition and stability with specific reference to the anaerobic bacterium Desulfovibrio desulfuricans. Biometals 20 (3-4):291-302. doi:10.1007/s10534-006-9059-2

Berns RS (2000) Billmeyer and Saltzman's principles of color technology. 3rd edn. Wiley, New York

Bradford MM (1976) A rapid and sensitive method for the quantitation of microgram quantities of protein utilizing the principle of protein-dye binding. Anal Biochem 72 (1-2):248-254. doi:10.1016/0003-2697(76)90527-3

Brown WRJ (1957) Color discrimination of twelve observers. J Opt Soc Am 47 (2):137-143. doi:10.1364/JOSA.47.000137

Bursakov SA, Carneiro C, Almendra MJ, Duarte RO, Caldeira J, Moura I, Moura JJ (1997) Enzymatic properties and effect of ionic strength on periplasmic nitrate reductase (NAP) from Desulfovibrio desulfuricans ATCC 27774. Biochem Biophys Res Commun 239 (3):816-822. doi:10.1006/bbrc.1997.7560

Buzzini P, Massonnet G (2004) A market study of green spray paints by Fourier transform infrared (FTIR) and Raman spectroscopy. Sci Justice 44 (3):123-131. doi:10.1016/S1355-0306(04)71704-9

Cappitelli F, Abbruscato P, Foladori P, Zanardini E, Ranalli G, Principi P, Villa F, Polo A, Sorlini C (2009) Detection and elimination of cyanobacteria from frescoes: the case of the St. Brizio Chapel (Orvieto Cathedral, Italy). Microb Ecol 57 (4):633-639. doi:10.1007/s00248-008-9441-4

Cappitelli F, Vicini S, Piaggio P, Abbruscato P, Princi E, Casadevall A, Nosanchuk JD, Zanardini E (2005) Investigation of fungal deterioration of synthetic paint binders using vibrational spectroscopic techniques. Macromol Biosci 5 (1):49-57. doi:10.1002/mabi.200400134

Cappitelli F, Zanardini E, Ranalli G, Mello E, Daffonchio D, Sorlini C (2006) Improved methodology for bioremoval of black crusts on historical stone artworks by use of sulfate-reducing bacteria. Appl Environ Microbiol 72 (5):3733-3737. doi:10.1128/AEM.72.5.3733-3737.2006 
Chen BY, Utgikar VP, Harmon SM, Tabak HH, Bishop DF, Govind R (2000) Studies on biosorption of zinc(II) and copper(II) on Desulfovibrio desulfuricans. Int Biodeter Biodegr 46 (1):11-18. doi:10.1016/S09648305(00)00054-8

CIE (1986) Publication 15-2: colorimetry. CIE Central Bureau, Vienna

El-Diwani G, El-Ibiari NN, Hawash SI (2009) Treatment of hazardous wastewater contaminated by nitrocellulose. J Hazard Mater 167 (1-3):830-834. doi:10.1016/j.jhazmat.2009.01.063

Freedman DL, Caenepeel BM, Kim BJ (1996) Biotransformation of nitrocellulose under methanogenic conditions. Water Sci Technol 34 (5-6):327-334. doi:10.1016/0273-1223(96)00662-2

Freedman DL, Cashwell JM, Kim BJ (2002) Biotransformation of explosive-grade nitrocellulose under denitrifying and sulfidogenic conditions. Waste Manage 22 (3):283-292. doi:10.1016/S0956-053X(01)00032-0

Giacomucci L, Bertoncello R, Salvadori O, Martini I, Favaro M, Villa F, Sorlini C, Cappitelli F (2011) Microbial deterioration of artistic tiles from the facade of the Grande Albergo Ausonia \& Hungaria (Venice, Italy). Microb Ecol 62 (2):287-298. doi:10.1007/s00248-011-9812-0

Govaert F, Bernard M (2004) Discriminating red spray paints by optical microscopy, Fourier transform infrared spectroscopy and X-ray fluorescence. Forensic Sci Int 140 (1):61-70. doi:10.1016/j.forsciint.2003.11.015

Hardeberg AY (1999) Acquisition and reproduction of color images: colorimetric and multispectral approaches. PhD, Ecole Nationale Superieure des Telecommunications, PhD Thesis

Haveman SA, Greene EA, Stilwell CP, Voordouw JK, Voordouw G (2004) Physiological and gene expression analysis of inhibition of Desulfovibrio vulgaris Hildenborough by nitrite. J Bacteriol 186 (23):7944-7950. doi:10.1128/Jb.186.23.7944-7950.2004

Keith SM, Herbert RA (1983) Dissimilatory nitrate reduction by a strain of Desulfovibrio desulfuricans. FEMS Microbiol Lett 18 (1-2):55-59. doi:10.1111/j.1574-6968.1983.tb00448.x

Kraft B, Strous M, Tegetmeyer HE (2011) Microbial nitrate respiration - Genes, enzymes and environmental distribution. J Biotechnol 155 (1):104-117. doi:10.1016/j.jbiotec.2010.12.025

Liu M-C, Costa C, Moura I (1994) Hexaheme nitrite reductase from Desulfovibrio desulfuricans (ATCC 27774). Methods Enzymol 243:303-319. doi:10.1016/0076-6879(94)43023-3

Macadam DL (1942) Visual Sensitivities to Color Differences in Daylight. J Opt Soc Am 32 (5):247-273. doi:10.1364/JOSA.32.000247

Marietou A, Griffiths L, Cole J (2009) Preferential reduction of the thermodynamically less favorable electron acceptor, sulfate, by a nitrate-reducing strain of the sulfate-reducing bacterium Desulfovibrio desulfuricans 27774. J Bacteriol 191 (3):882-889. doi:10.1128/jb.01171-08

Mitchell GJ, Jones JG, Cole JA (1986) Distribution and regulation of nitrate and nitrite reduction by Desulfovibrio and Desulfotomaculum species. Arch Microbiol 144 (1):35-40. doi:10.1007/BF00454953

Moura I, Bursakov S, Costa C, Moura JJ (1997) Nitrate and nitrite utilization in sulfate-reducing bacteria. Anaerobe 3 (5):279-290. doi:10.1006/anae.1997.0093

Moura JJG, Gonzalez P, Moura I, Fauque G, Barton LL, Hamilton WA (2007) Dissimilatory nitrate and nitrite ammonification by sulphate-reducing eubacteria. In: Barton LL, Hamilton WA (eds) Sulphate-reducing bacteria. Environmental and engineered systems. Cambridge University Press, Cambridge, pp 241-264

Pepe O, Sannino L, Palomba S, Anastasio M, Blaiotta G, Villani F, Moschetti G (2010) Heterotrophic microorganisms in deteriorated medieval wall paintings in southern Italian churches. Microbiol Res 165 (1):21-32. doi:10.1016/j.micres.2008.03.005

Pereira IAC, LeGall J, Xavier AV, Teixeira M (2000) Characterization of a heme c nitrite reductase from a nonammonifying microorganism, Desulfovibrio vulgaris Hildenborough. BBA-Protein Struct M 1481 (1):119130. doi:10.1016/S0167-4838(00)00111-4

Petrova OE, Tarasova NB, Davydova MN (2010) On hydrolysis of cellulose and nitrocellulose under sulfate-reducing conditions. World J Microbiol Biotechnol 26 (1):189-192. doi:10.1007/s11274-009-0156-6

Petrova OE, Tarasova NB, Alyabyev AJ, Davydova MN, Loseva NL (2006) Calorimetric studies of the growth of Desulfovibrio desulfuricans in the presence of nitrocellulose. Thermochim Acta 445 (1):67-69. doi:10.1016/j.tca.2005.09.017

Petrova OE, Tarasova NB, Davydova MN (2002) Biotechnological potential of sulfate-reducing bacteria for transformation of nitrocellulose. Anaerobe 8 (6):315-317. doi:10.1016/S9964(03)00029-5

Prieto B, Sanmartín P, Pereira-Pardo L, Silva B (2011) Recovery of the traditional colours of painted woodwork in the Historical Centre of Lugo (NW Spain). J Cult Herit 12 (3):279-286. doi:10.1016/j.culher.2010.12.009 
Prieto B, Sanmartín P, Silva B, Martínez-Verdú F (2010) Measuring the color of granite rocks: a proposed procedure. Color Res Appl 35 (5):368-375. doi:10.1002/col.20579

Ranalli G, Recchiuti JE, Grazia L, Del Puppo E (1998) Bioluminescence and impedance monitoring to detect the activity of starter cultures during frozen storage. Ann Microbiol 48 (2):169-180

Ranalli G, Zanardini E, Pasini P, Roda A (2003) Rapid biodeteriogen and biocide diagnosis on artwork: a bioluminescent low-light imaging technique. Ann Microbiol 53 (1):1-13

Sanmartin P, Villa F, Silva B, Cappitelli F, Prieto B (2011) Color measurements as a reliable method for estimating chlorophyll degradation to phaeopigments. Biodegradation 22 (4):763-771. doi:10.1007/s10532-010-9402-8

Segalini S, Chirico AD, Depinto G, Pegoraro M Antigraffiti removers and antigraffiti coatings. In: XXV Fatipec Congress, Turin, 2000. pp 323-337

Seitz HJ, Cypionka H (1986) Chemolithotrophic growth of Desulfovibrio desulfuricans with hydrogen cCoupled to ammonification of nitrate or nitrite. Arch Microbiol 146 (1):63-67. doi:10.1007/BF00690160

Simon J (2002) Enzymology and bioenergetics of respiratory nitrite ammonification. Fems Microbiol Rev 26 (3):285309. doi:10.1111/j.1574-6976.2002.tb00616.x

Slack RJ, Gronow JR, Voulvoulis N (2005) Household hazardous waste in municipal landfills: contaminants in leachate. Sci Total Environ 337 (1-3):119-137. doi:10.1016/j.scitotenv.2004.07.002

Souza JVB, da Silva ES, da Silva FT, Paiva TCB (2005) Fungal treatment of a delignification effluent from a nitrocellulose industry. Bioresource Technol 96 (17):1936-1942. doi:10.1016/j.biortech.2005.01.027

Stoye D, Freitag W (1998) Introduction. In: Stoye D, Freitag W (eds) Paints, coatings, and solvents. 2nd edn. Wiley WCH, Weinheim, pp 1-10

Tarasova NB, Gorshkov OV, Petrova OE (2009) Activity of nitrate reductase in Desulfovibrio vulgaris VKM 1388. Microbiolog 78 (2):160-164. doi:10.1134/S0026261709020040

Tarasova NB, Petrova OE, Davydova MN, Khairutdinov BI, Klochkov VV (2004) Changes in the nitrocellulose molecule induced by sulfate-reducing bacteria Desulfovibrio desulfuricans 1,388 . The enzymes participating in this process. Biochemistry (Mosc) 69 (7):809-812. doi:10.1023/B:BIRY.0000040208.67569.d1

Tarasova NB, Petrova OE, Faizullin DA, Davydova MN (2005) FTIR-spectroscopic studies of the fine structure of nitrocellulose treated by Desulfovibrio desulfuricans. Anaerobe 11 (6):312-314. doi:10.1016/j.anaerobe.2005.03.002

Völz HG (2001) Industrial color testing. Wiley-VCH, Weinheim

Wyszecki G, Stiles WS (1982) Color science, concepts and methods, quantitative data and formulae. 2nd edn. Wiley, New York

Zieba-Palus J (2005) Examination of spray paints by the use of reflection technique of microinfrared spectroscopy. $\mathbf{J}$ Mol Struct 744-747:229-234. doi:10.1016/j.molstruc.2004.12.027 